\title{
The effect of mast cells on the biological characteristics of prostate cancer cells
}

\author{
ZHIFANG MA, LIANG YUE, ZHAOLIANG XU, SHENG ZENG, YUKUN MA, ZHUOPING LI, \\ WEI LI, DONGWEN WANG
}

Department of Urology, First Hospital of Shanxi Medical University, Taiyuan, China

\begin{abstract}
Aim of the study: To investigate the effects of mast cells on the proliferation, invasion, and metastasis of prostate cancer cells.

Material and methods: The mast cell P815 and prostate cancer LNCaP cells were chosen using a Transwell chamber to construct a two-cell cocultured in vitro model to observe the migration of mast cells to prostate cancer cells.

Results: In the migration experiment, the migration rate of mast cells from the experimental group (\%) was $10.167 \pm 0.833$, the mast cell migration rate (\%) of the control group was $0.833 \pm 0.208$, and the difference was statistically significant $(p<0.05)$. The MTT test showed that the OD value of cells in each group over time increased gradually, and $24 \mathrm{~h}$ after LNCaP cells were cocultured with different concentrations of mast cells, the OD value was significantly higher than that of the control group $(p<0.05)$. QRT-PCR and western blot results showed that, compared with the control group, E-cad expression from the experimental group was significantly weakened; $N$-cad and vimentin expression increased $(p<0.05)$, and c-kit and SCF expression from experimental group were significantly higher than that of the control group $(p<0.05)$. After the addition of $c$-kit neutralising antibodies, compared with the control group, the mast cell migration rate of experimental group decreased significantly and prostate cancer cell proliferation significantly decreased $(p<0.05)$.

Conclusions: Mast cells could promote the proliferation of prostate cancer cells and the occurrence of epithelial mesenchymal transition (EMT), which could promote the invasion and metastasis of prostate cancer cells.
\end{abstract}

Key words: mast cells, prostate cancer cells, epithelial mesenchymal transition, SCF/c-kit pathway, C-kit inhibitor.

(Centr Eur J Immunol 2018; 43 (1): 1-8)

\section{Introduction}

Prostate cancer $(\mathrm{PCa})$ incidence rates show an upward trend year after year. According to statistics, in the United States, in 2010217,000 men were diagnosed with prostate cancer, and then there were 32,000 cases of men dying from metastatic PCa [1]. With the aging of the population and the change of diet structure, the incidence of the disease is increasing year by year, and it is estimated that by 2050 the PCa incidence rate will increase 2.5 fold [2]. The aetiology of $\mathrm{PCa}$ is complex and may be related to lifestyle, age, race, environment, heredity, sex hormones, and other factors. In recent years, more and more studies have suggested that chronic inflammation of the prostate might be an important factor in the occurrence and progression of PCa.
Inflammation provides a suitable environment for the growth of tumours. In the nineteenth century it was noted that tumours often occur at the site of chronic inflammation [3]. It was also reported that many tumours are closely related to inflammation: bronchitis and lung cancer; cancer of the bladder and cystitis; chronic ulcerative colitis and colon cancer; hepatitis B and C virus-induced chronic hepatitis and hepatocellular carcinoma; and Epstein Barr virus infection and nasopharyngeal carcinoma [4]. Therefore, it was speculated that chronic inflammation of the prostate might be related to the occurrence and development of prostate cancer [5, 6]. Consistent with this, a study found that in five years of follow-up the incidence of prostate cancer in patients with chronic prostatitis was higher [7], and that in a prospective study of 5821 males with mean age 65 years in a community in California, USA, the correlation ratio between prostatitis and prostate cancer was 5.4 [8].

Correspondence: Zhifang Ma, Department of Urology, First Hospital of Shanxi Medical University, Taiyuan 030001, China,

e-mail: mazf20141008@163.com

Submitted: 25.02.2016; Accepted: 11.05.2016 
In addition, by methods of meta-analysis, it was shown that there was a positive correlation between chronic bacterial prostatitis and prostate cancer [9]. These studies suggested that chronic inflammation of the prostate was closely related to prostate cancer.

So, in this study, to investigate the effects of inflammatory mast cells on the proliferation and invasion and metastasis of prostate cancer cells, we constructed a coculture model of mast cells and prostate cancer cells in vitro, and clarified the phenomena of the migration of mast cells to prostate cancer LNCaP cells, promoting the proliferation of tumours cells, and then explored the possible mechanism.

\section{Material and methods}

\section{Material}

Human prostate cancer LNCaP cell line and mouse mast cell tumour P815 cell line were purchased from the Chinese Academy of Sciences, Shanghai Institute of Life Sciences cell resource centre. DMEM/F12 (1:1) culture medium, RPMI-1640 medium, and the MTT reagent box were purchased from Wuhan Boster Biological Technology Co., Ltd.; foetal bovine serum (FBS) was purchased from Hyclone Laboratories, Inc. in the United States; the Transwell chamber and plates were purchased from Corning, Inc.; total cell protein extraction reagent and gel for the preparation kit were purchased from Taiyuan biological Co., Ltd.; Rabbit anti-rat SCF monoclonal antibody and Rabbit anti-mouse c-kit monoclonal antibody were purchased from Cell Signaling Technology, Inc. (USA).

\section{Cell culture}

Human prostate cancer LNCaP cell line and mouse mast cell tumour P815 cell line were maintained in DMEM/F12 (1: 1) culture medium or RPMI-1640 supplemented with $10 \%(\mathrm{v} / \mathrm{v})$ foetal bovine serum (Hyclone) and antibiotics $(100 \mathrm{U} / \mathrm{ml}$ penicillin and $100 \mu \mathrm{g} / \mathrm{ml}$ streptomycin) (Hyclone) at $37^{\circ} \mathrm{C}$ in an atmosphere of $5 \% \mathrm{CO}_{2}$.

\section{To establish an in vitro cell coculture model for cell migration test}

The 24 Transwell chamber was used to construct the coculture model of LNCaP cells and P815 cells. The prostate cancer LNCaP cells was selected in the logarithmic growth stages, and after $0.25 \%$ trypsin- $0.02 \%$ EDTA digestion, transferred to $10-\mathrm{ml}$ centrifuge tubes at $1000 \mathrm{rpm}$ centrifuge for $5 \mathrm{~min}$. Then, after discarding the supernatant, the cells were counted and the cell concentration was adjusted to $5 \times 10^{5} / \mathrm{ml}$; P815 cells that showed cell growth in good condition were collected and moved into $10-\mathrm{ml}$ centrifuge tubes at $1000 \mathrm{rpm}$ centrifugation for $5 \mathrm{~min}$. After discarding the supernatant, the cells were counted and the cell concentration was adjusted to $5 \times 10^{5} / \mathrm{ml} .1 \times 10^{5}$ prostate cancer LNCaP cells were moved into the lower chamber, and cell suspensions were allocated to $0.6 \mathrm{ml}$ to be adherent to prostate cancer cell line LNCaP; ventricular supernatant and rejoin the equivalent of new culture medium; supraventricular join $6 \times 10^{4} \mathrm{P} 815$ cells, volume of $0.2 \mathrm{ml}$; Transwell chamber into $37^{\circ} \mathrm{C}, 5 \% \mathrm{CO}_{2}$ incubation cultured for $24 \mathrm{~h} ; 24 \mathrm{~h}$ after coculture, cell numbers of mast cells was migrated to the lower chamber, and counted, and calculation of mast cell migration rate was performed.

\section{MTT test to assertain the effect of mast cells on the proliferation of prostate cancer cells}

Prostate cancer cells with cell growth in good condition were selected. After $0.25 \%$ trypsin digestion, single cell suspension was resuspended and adjusted to the concentration $1 \times 10^{5} / \mathrm{ml} ; 4 \times 10^{3}$ cells per hole were seeded in 96 well plates, each with a volume of $100 \mu \mathrm{l}$, at $37^{\circ} \mathrm{C}$ and $5 \% \mathrm{CO}_{2}$ in a constant temperature incubator, for prostate cancer cell adherence; discard the old medium, to join the new medium; mast cells with different concentrations, adjust the final cell concentration was $10^{4}, 10^{5}$, and $10^{6} / \mathrm{ml}$, the concentration of repeat 5 holes, set at the same time without big negative cells of the control group, in $37^{\circ} \mathrm{C}$ and $5 \% \mathrm{CO}_{2}$ in a constant temperature incubator culture; 3 well plates were incubated for $12 \mathrm{~h}, 24 \mathrm{~h}, 48 \mathrm{~h}$, and the medium containing mast cell supernatant was discarded, each hole by adding MTT solution $(5 \mathrm{mg} / \mathrm{ml}) 20 \mu \mathrm{l}$, adding $100 \mu \mathrm{L}$ medium into the culture medium, at $37^{\circ} \mathrm{C}$ and $5 \% \mathrm{CO}_{2}$ in a constant temperature incubator for $4 \mathrm{~h}$, the termination of the culture; careful ceiling abandoned hole in the culture supernatant, each hole by adding $150 \mu \mathrm{l}$ DMSO, oscillation for $10 \mathrm{~min}$, the crystals dissolve fully; $490 \mathrm{~nm}$ wavelength was chosen, in enzyme linked immunoassay instrument determination of each hole light absorption value (OD), recording the results; with time as the horizontal axis, OD value for the vertical axis drawing cell growth curve.

\section{qRT-PCR mRNA expression analysis of E-cad, $\mathrm{N}$-cad, vimentin, and SCF of LNCaP cells, and c-kit of mast cells}

Real time quantitative RT-PCR (qRT-PCR) was performed with SYBR Green to investigate the expression of E-cad, N-cad, vimentin, and SCF of LNCaP cells, and c-kit of mast cells. The qRT-PCR amplifications were carried out in triplicate in a total volume of $25 \mu$ containing $12.5 \mu \mathrm{l}$ SYBR Green $2 \times$ Supermix, $1 \mu$ of the $1: 5$ diluted cDNA, $1 \mu \mathrm{l}$ each of forward and reverse primers, and $9.5 \mu \mathrm{l}$ PCR grade water. The qRT-PCR program was $50^{\circ} \mathrm{C}$ for $2 \mathrm{~min}, 95^{\circ} \mathrm{C}$ for $10 \mathrm{~min}$, followed by 40 cycles of $94^{\circ} \mathrm{C}$ for $15 \mathrm{~s}$, and $55^{\circ} \mathrm{C}$ for $30 \mathrm{~s}$. All analyses were based on the cycle threshold (CT) values of the PCR products. The CT was defined as the PCR cycle at which the fluorescence signal crossed a threshold line that was placed in the exponential phase of the amplification curve. Melting curve 
analysis of amplification products was performed at the end of each PCR reaction to confirm that only one PCR product was amplified and detected. Differences in the CT for the target and the internal control, called ${ }^{\Delta} \mathrm{CT}$, were calculated to normalise the differences in the amount of total nucleic acid added to each reaction and the efficiency of the RT-PCR. The ${ }^{\wedge} \mathrm{CT}$ for each sample was subtracted from the ${ }^{\Delta} \mathrm{CT}$ of the calibrator; the difference was called the ${ }^{\Delta \Delta} \mathrm{CT}$ value. Gene expression was assessed using two to three technical replicates and three biological replicates. The beta-actin was used as an internal reference to normalise each sample. Fold-change was calculated using the $2^{-\Delta \Delta} \mathrm{Ct}$ method. The primers used are shown below:

- E-cad, forward primer: 5'-GTCTCTCTCACCACCTCCACAG-3', and reverse primer: 5'-CTCGGACACTTCCACTCTCTTT-3',

- N-cad, forward primer: 5'-AGGGTGGACGTCATTGTAGC-3', and reverse primer: 5'-CTGTTGGGGTCTGTCAGGAT-3',

- vimentin, forward primer: 5'-GCGAGGAGAGCAGGATTTCT-3', and reverse primer: 5'-GGTATCAACCAGAGGGAGTGAA-3',

- SCF, forward primer: 5'-ATAGTGGATGACCTTGTGGAG-3', and reverse primer: 5'-TGTGACACTGACTCTGGAATC-3',

- c-kit, forward primer: 5'-TTATGCACTGATCCGGGC-3', and reverse primer: 5'-ACCAGCGTGTCGTTGTCT-3',

- beta-actin, forward primer: 5'-TGGCACCCAGCACAATGAA-3', and reverse primer: 5'-CTAAGTCATAGTCCGCCTAGAAGCA-3'.

\section{Protein expression analysis of E-cad, N-cad, vimentin, and SCF of LNCaP cells, and c-kit of mast cells}

The western blotting mothed was used to investigate the protein expression of E-cad, N-cad, vimentin, and SCF of LNCaP cells, and c-kit of mast cells. For western blotting, the same protein sample was separated on a $12 \%$ polyacrylamide gel under reducing conditions and then transferred to a polyvinylidene difluoride (PVDF) membrane (Roche Applied Science) and probed with anti-E-cad, N-cad, vimentin, $\mathrm{SCF}$, and c-kit primary antibodies, respectively. The blots were developed using a TMB immunoblotting system. AlphaView image analysis software was used to analyse the relative expression of the target protein, which was expressed by the grey value of the target protein/beta-actin.

\section{The mast cell migration rate and the proliferation of prostate cancer cell line were measured after the addition of c-kit neutralising antibody}

The in vitro cell coculture model was used to investigate the mast cell migration rate and the proliferation of prostate cancer cell line after the addition of c-kit neutral- ising antibody. The experiments were divided into two groups: the control group with control antibody and the experimental group with c-kit neutralising antibody, cocultured for $24 \mathrm{~h}$, and then the migration rate of mast cells was calculated in the two groups, and MTT colorimetric assay was used to measure the growth of tumour cells.

\section{Statistical analysis}

SPSS17.0 software was used to deal with the measurement data. Two independent samples were compared with $t$ test. $P<0.05$ was considered as the difference with statistical significance. Similar results were observed in at least three independent experiments.

\section{Results}

\section{The effects of prostate cancer cells on mast cell migration}

To examine the effects of prostate cancer cells on mast cell migration, an in vitro cell coculture model was established and cell migration test was performed. As shown in Figure 1 and Table 1, $24 \mathrm{~h}$ after coculturing, under high magnification observation of mast cell group migration, compared with the control group, the migration rate of mast cells in the experimental group significantly increased, and the difference was statistically significant $(p<0.01)$. These data suggested that prostate cancer cells could promote the mast cell migration.

\section{The effects of mast cells on prostate cancer cell proliferation}

To investigate effects of mast cells on prostate cancer cell proliferation, the MTT test was done. As shown in Figure 2, $12 \mathrm{~h}$ after prostate cancer cells were cocultured with different concentrations of mast cells, compared with that of the control group, the OD value of the experimental group had changes of no statistical difference $(p>0.05)$, but $24 \mathrm{~h}$ and $48 \mathrm{~h}$ after coculture, the OD value increased significantly $(p<0.05)$. These data suggested that, with the increase of mast cell concentration, mast cells could promote tumour cell proliferation.

\section{The epithelial mesenchymal matter transformation markers, E-cad, N-cad, and vimentin, in $\mathrm{LNCaP}$ cells were measured at the mRNA and protein level}

To investigate the mRNA expression of the epithelial mesenchymal matter transformation markers, including E-cad, N-cad, and vimentin, in LNCaP cells, the qRT-PCR method was used. As shown in Table 2, compared with that of the control group, in the experimental group E-cad mRNA expression was significantly weakened, $\mathrm{N}$-cad and 

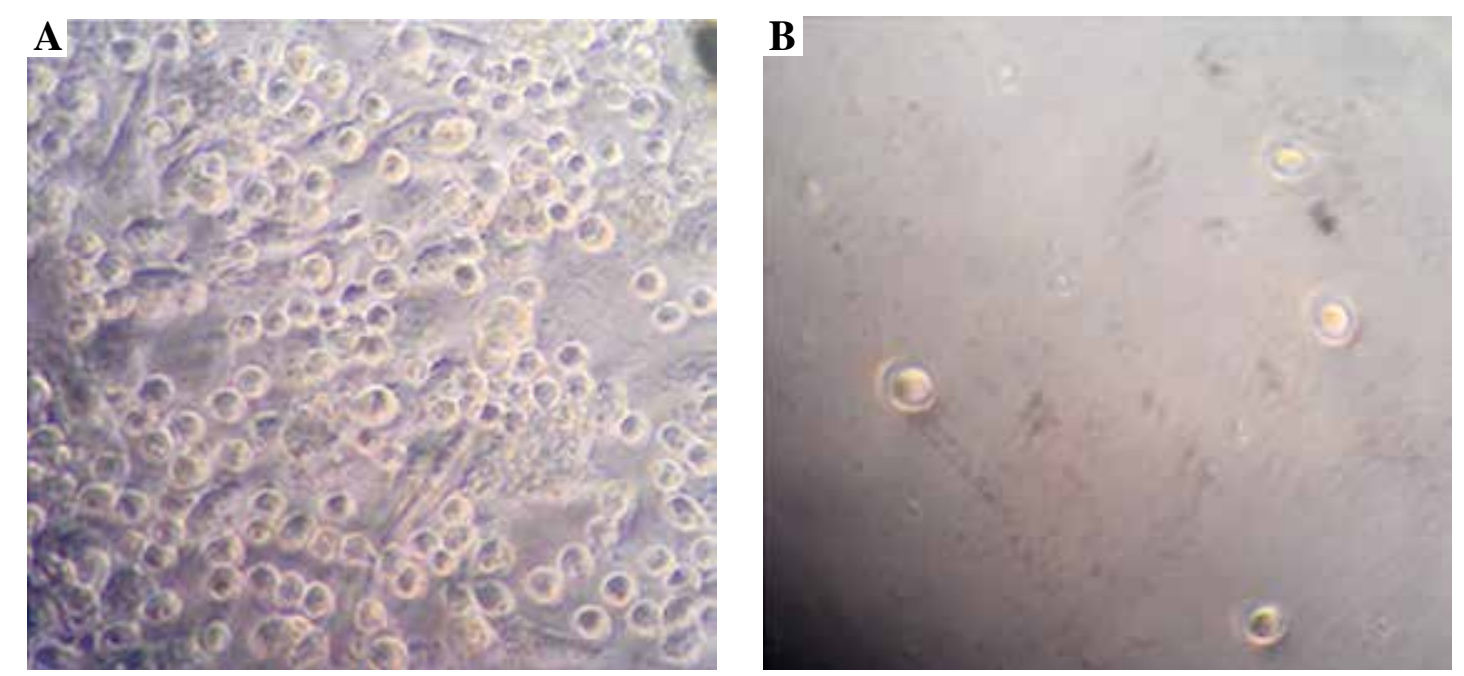

Fig. 1. Prostate cancer cells could promote mast cell migration. The in vitro cell coculture model was established, as shown in the Material and methods section. $24 \mathrm{~h}$ after coculturing, the effects of prostate cancer cells on mast cell migration of experimental group (A) and control group (B), were observed under high magnification $(400 \times)$, as shown in the Material and methods section

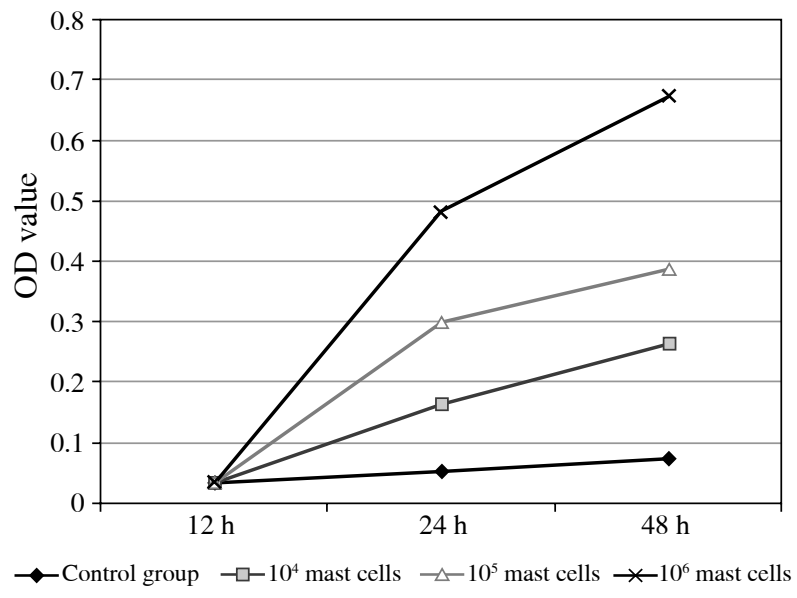

Fig. 2. The proliferation of prostate cancer cells could be promoted by mast cells. The prostate cancer cells were cocultured with different concentrations of mast cells, and the OD values of each group were tested by methods of MTT, as shown in the Material and methods section

Table 3. The mRNA expression (SCF and c-kit) in LNCaP cells and mast cells from the experimental group and control group

\begin{tabular}{lcc}
\hline Group & SCF & c-kit \\
\hline Control group & $0.913 \pm 0.108$ & $1.209 \pm 0.124$ \\
\hline Experimental group & $1.647 \pm 0.339$ & $1.672 \pm 0.167$ \\
\hline$p$ & 0.023 & 0.018 \\
\hline$p<0.05$ is considered as the difference with statistical significance
\end{tabular}

Table 1. Comparison of the migration rate (\%) of mast cells between the experimental group and control group

\begin{tabular}{lcc}
\hline Group & $\overline{\boldsymbol{x}} \pm \boldsymbol{s}$ & $\boldsymbol{p}$ \\
\hline Experimental group & $10.167 \pm 0.833$ & \\
\hline Control group & $0.833 \pm 0.208$ & $<0.01$ \\
\hline$p<0.05$ is considered as the difference with statistical significance
\end{tabular}

Table 2. The epithelial mesenchymal matter transformation marker mRNA expression (N-cad, E-cad, vimentin) in LNCaP cells from the experimental group and control group

\begin{tabular}{lccc}
\hline Group & E-cad & N-cad & Vimentin \\
\hline $\begin{array}{l}\text { Experimental } \\
\text { group }\end{array}$ & $2.743 \pm 0.475$ & $0.802 \pm 0.140$ & $0.692 \pm 0.723$ \\
\hline Control group & $0.711 \pm 0.133$ & $1.851 \pm 0.189$ & $0.927 \pm 0.472$ \\
\hline$p$ & 0.002 & 0.001 & 0.009 \\
\hline$p<0.05$ is considered as the difference with statistical significance
\end{tabular}

vimentin mRNA expression significantly increased, and the difference was statistically significant $(p<0.05)$.

In addition, to show the protein expression of the epithelial mesenchymal matter transformation markers, including E-cad, N-cad, and vimentin, in LNCaP cells, western blot method was used. As shown in Fig. 3, compared with that of the control group, in the experimental group E-cad protein expression was significantly weakened, $\mathrm{N}$-cad and vimentin protein expression increased, and the difference was statistically significant $(p<0.05)$. 


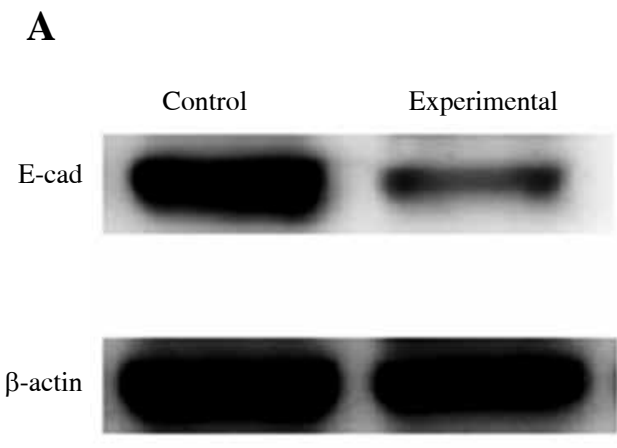

B

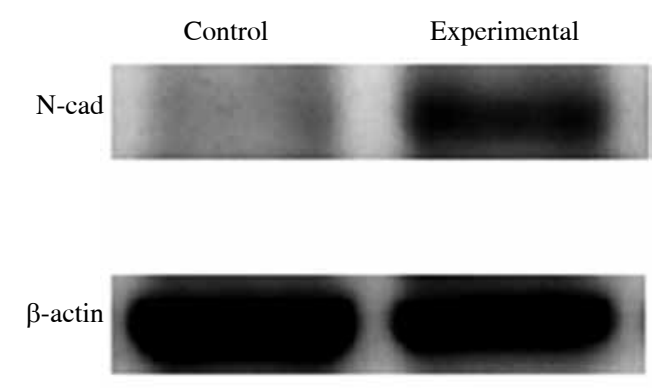

C
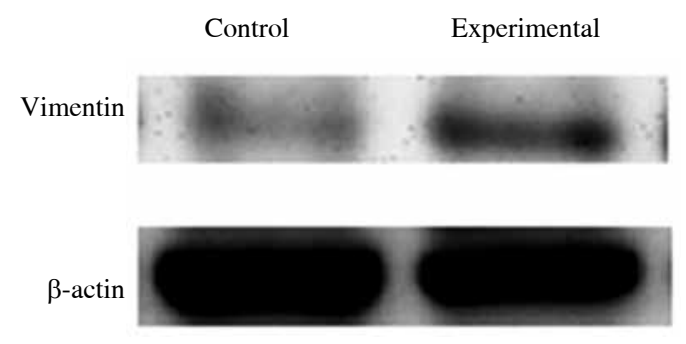
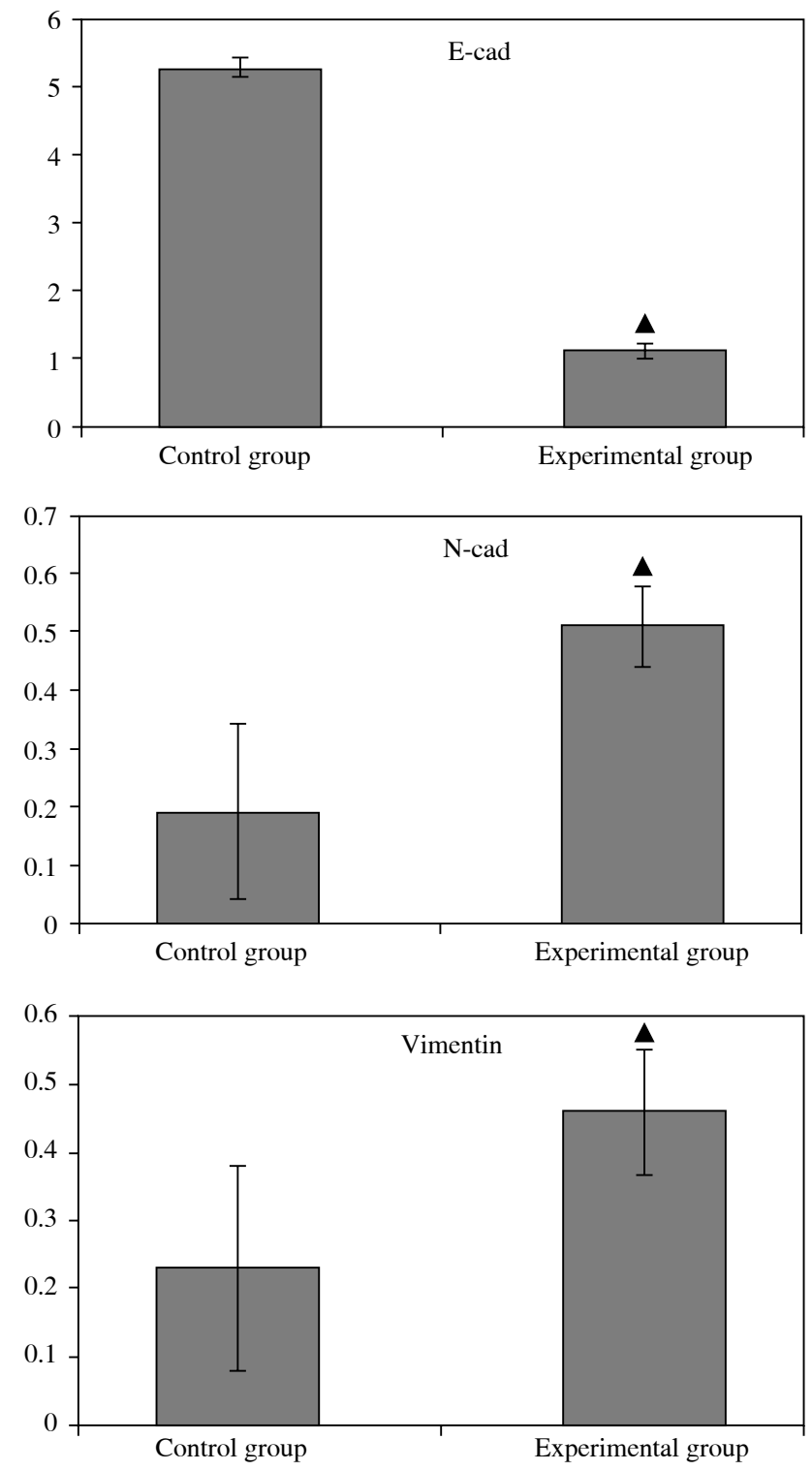

Fig. 3. The epithelial mesenchymal matter transformation markers, E-cad, N-cad, and vimentin in LNCaP cells were measured at the protein level. The protein expression of E-cad (A), N-cad (B), and vimentin (C) of LNCaP cells from the control group and experimental group were measured by western blot method, as shown in the Material and methods section

\section{The mRNA and protein expression of SCF in $\mathrm{LNCaP}$ cells and c-kit in mast cells were examined}

The qRT-PCR and western blot methods were used to investigate the mRNA and protein expression of SCF in LNCaP cells and c-kit in mast cells. As shown in Table 3 and Figure 4, the mRNA and protein expression of SCF and c-kit in the experimental group was significantly higher than that in the control group, and the difference was statistically significant $(p<0.05)$.

\section{Mast cell migration rate and $\mathrm{LNCaP}$ cell proliferation were measured after the addition of the c-kit neutralising antibody}

To further investigate the roles of c-kit in mast cell migration and LNCaP cell proliferation in the model of cell coculture in vitro, c-kit neutralising antibody was added to the experimental group, and the same type of control antibody was added to the control group, and then $24 \mathrm{~h}$ after coculture the migration rate of the mast cells and LNCaP cell proliferation in the two groups were examined. 

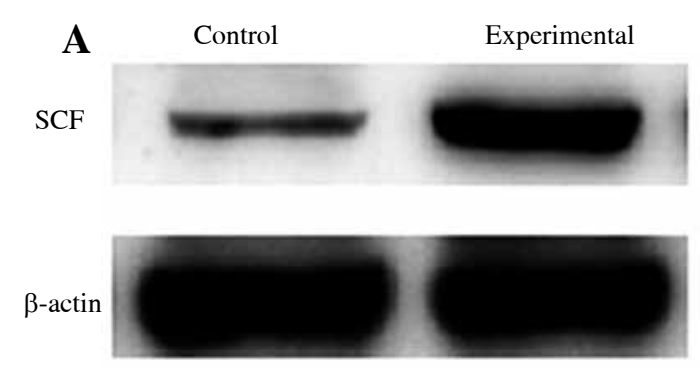
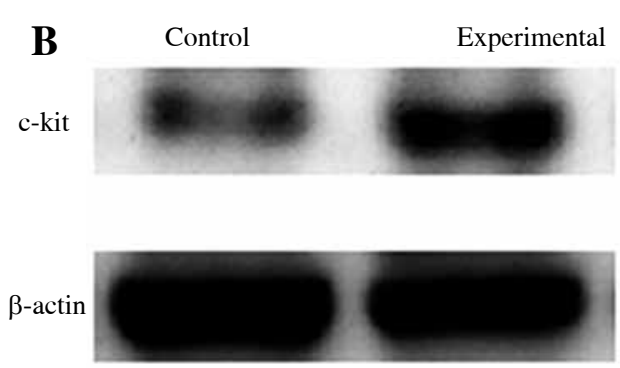

Fig. 4. The protein expression of SCF in LNCaP cells (A) and c-kit in mast cells (B) from the control group and experimental group were measured by western blot method, as shown in the Material and methods section
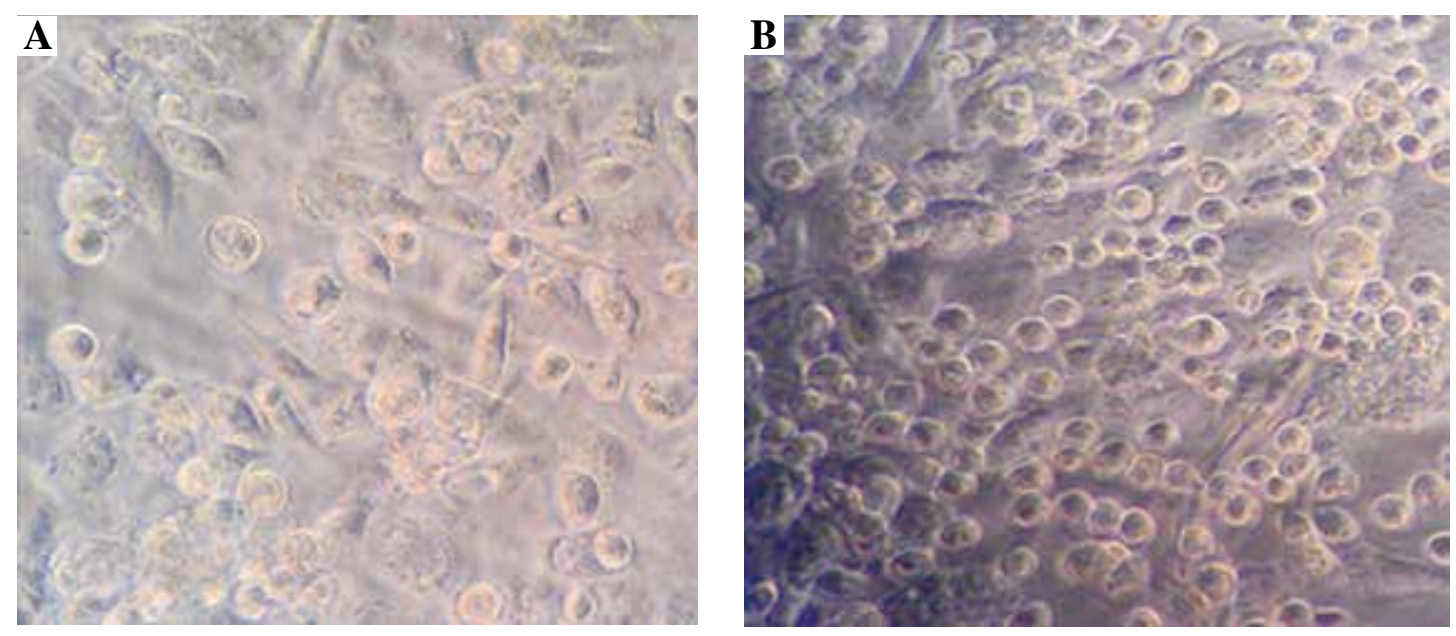

Fig. 5. The mast cell migration could be inhibited by the c-kit neutralising antibody. The c-kit neutralising antibody was added to the experimental group, and the control group was given the same type of control antibody, and then $24 \mathrm{~h}$ after coculture, the mast cell migration of experimental group (A) and control group (B) was observed under high magnification $(400 \times)$, as shown in the Material and methods section

As shown in Figure 5 and Table 4, compared with the control group the migration rate of mast cells in the experimental group was significantly lower $(p<0.05)$. MTT assay was used to measure LNCaP cell growth in the two groups, and when compared with that of the control group, the OD value of the tumour cells in the experimental group significantly decreased $(p<0.05)$ (Table 5$)$. These data suggested that the c-kit neutralising antibody could inhibit mast cell migration and tumour cell proliferation.

\section{Discussion}

In this study, the mast cell P815 and prostate cancer LNCaP cells were chosen using Transwell chambers to construct a two-cell cocultured in vitro model to observe the migration of the mast cells to prostate cancer cells, and we have shown that the inflammatory mast cells could promote the proliferation of prostate cancer cells and the occurrence of epithelial mesenchymal transition (EMT), which could promote the invasion and metastasis of prostate cancer cells.

The effects of inflammation on prostate cancer were mainly through the local inflammatory cells, which could release cytokines and produce a large amount of active oxygen species (reactive oxygen species, RNS ROS) and reactive nitrogen species, which formed the tumour micro environment and then stimulated the growth of prostate cancer cells in vitro, as well as blood vessels and lymphatic vessel formation, and promoted prostate cancer cell invasion and metastasis; important inflammatory cells included mast cells (mast cells and MC), tumour-associated fibroblasts (cancer-associated fibroblast, CAF), etc. [10].

So far, there have only been a few studies about the effects of mast cells on prostate cancer cells. These studies 
Table 4. Comparison of the mast cell migration rate of the experimental group and control group after the addition of c-kit neutralising antibody

\begin{tabular}{lcc}
\hline Group & $\overline{\boldsymbol{x}} \pm \boldsymbol{s}$ & $\boldsymbol{p}$ \\
\hline Experimental group & $1.133 \pm 0.451$ & 0.001 \\
\hline Control group & $9.567 \pm 1.484$ & \\
\hline$p<0.05$ is considered as the difference with statistical significance
\end{tabular}

have shown that mast cells can stimulate the growth of $\mathrm{PCa}$ in several different animal models, but the roles of mast cells in PCa is not clear. It was found that mast cells were infiltrated in the primary tumour and the edge of the healthy tissue [11-13]. The signalling pathway of proliferation and differentiation of PCa cells was closely related to c-kit [14]. Stem cell factor (SFC) was found in the 1990s, as kit ligand [15], mast cell growth factor [16], and stem cell factor [17], now known as stem cell factor. Consistent with this, in this study, by QRT-PCR assay and western blot experiments, the mRNA and protein expression of SCF and c-kit in the experimental group was significantly higher than that seen in the control group, and the difference was statistically significant $(p<0.05)$. And through Transwell experiment to successfully establish the coculture model of mast cells and prostate cancer cells in vitro, and with the use of c-kit neutralising antibodies, the migration of the mast cells to the prostate cancer tumour cell was significantly inhibited, then to block the prostate cancer tumour cell growth. These data showed that SCF/c-kit signalling pathway hastened the main role in the process of promoting the effect of mast cells on prostate cancer cells.

It was shown that mast cells could be continuously activated by SCF/c-kit signalling pathway, leading to NF kappa B pathway, sustained activation of MAPK/ ERK pathway, and the hedgehog signalling pathway of multiple signalling pathways, to cause the abnormal expression of target genes, and abnormal expression of these genes might be associated with prostate cancer occurrence [18-21]. The specific mechanisms of these signalling pathways would be our further research direction.

Under certain physiological or pathological conditions, some epithelial cell polarity changes could be transformed into highly active, free movement of mesenchymal cells in the matrix, which is the process of epithelial mesenchymal transition (EMT). The basis of tumour invasion and metastasis comprises the two aspects of cell adhesion and cell movement. It was found that EMT tumour cells had stronger invasion and metastasis [22]. It was also reported that, through the construction of macrophages and prostate cancer cells in the in vitro and in vivo coculture model, the macrophages could promote the proliferation of prostate cancer cells, and the epithelial mesenchymal transition had a certain role in prostate cancer invasion and metastasis mechanisms [23]. These studies suggested
Table 5. Comparison of the LNCaP cell OD values of the experimental group and the control group after the addition of c-kit neutralising antibody

\begin{tabular}{lcc}
\hline Group & $\overline{\boldsymbol{x}} \pm \boldsymbol{s}$ & $\boldsymbol{p}$ \\
\hline Control group & $1.258 \pm 0.149$ & 0.007 \\
\hline Experimental group & $0.547 \pm 0.195$ & \\
\hline$p<0.05$ is considered as the difference with statistical significance
\end{tabular}

that inflammation might be closely related to the occurrence and development of PCa. Currently, regarding the relationship between inflammatory cells and malignant tumours, there have been relatively few studies on mast cells. Studies have shown that in several different animal tumour models, mast cells could stimulate the growth of tumour, but their role in PCa is unclear. Therefore, it is of great significance to study the value of mast cells in the interaction between inflammation and PCa.

In conclusion, this study showed that after coculture, the prostate cancer epithelial cell polarity marker E-cad was down-regulated, and $\mathrm{N}$-cad and vimentin expression of characteristic signs of interstitial cells was increased, indicating that mast cells had a certain role in promoting EMT of prostate cancer cells, and might promote invasion and metastasis of prostate cancer.

\section{Acknowledgements}

This work was supported by grants from the Construction Project of National Key Clinical Department of Urology (2012); Program for tackling key problems in science and technology supported by Shanxi Health and Family Planning Commission (2011027).

The authors declare no conflict of interests.

\section{References}

1. Jemal A, Siegel R, Xu J, et al. (2010): Cancer statistics. CA Cancer J Clin 60: 277-300.

2. Hayat MJ, Howlader N, Reichman ME, et al. (2007): Cancer statistics, trends, and multiple primary cancer analyses from the Surveillance, Epidemiology, and End Results (SEER) Program. Oncologist 12: 20-37.

3. Clevers H (2004): At the crossroads of inflammation and cancer. Cell 118: 671-674.

4. Coussens LM, Werb Z (2002): Inflammation and cancer. Nature 420: 860-867.

5. De Marzo AM, DeWeese TL, Platz EA, et al. (2004): Pathological and molecular mechanisms of prostate carcinogenesis: implications for diagnosis, detection, prevention, and treatment. Cell Biochem 91: 459-477.

6. De Marzo AM, Marchi VL, Epstein JI, et al. (1999): Proliferative inflammatory atrophy of the prostate: implications for prostatic carcinogenesis. Am J Pathol 155: 1985-1992. 
7. MacLennan GT, MacLennan GT, Eisenberg R, et al. (2006): The influence of chronic inflammation in prostatic carcinogenesis: A 5-year followupstudy. J Urol 176: 1012-1016.

8. Daniel NA, Ewing SK, Zmuda JM, et al. (2005): Correlates and prevalence of prostatitis in a large community-base cohort of Order men. Urology 66: 964-970.

9. Klein EA, Silverman R (2008): Inflammation, infection, and prostate cancer. Curr Opin Urol 18: 315-319.

10. McDonald PC, Chafe SC, Dedhar S, et al. (2016): Overcoming Hypoxia-Mediated Tumor Progression: Combinatorial Approaches Targeting pH Regulation, Angiogenesis and Immune Dysfunction. Front Cell Dev Biol 4: 27.

11. Craig M, Ying C, Loberg RD (2008): Co-inoculation of prostate cancer cells with U937 enhances tumor growth and angiogenesis in vivo. J Cell Biochem 103:1-8.

12. Vyas H, Krishnaswamy GP (2006): Ehrlich's "Mastzellen"from aniline dyes to DNA chip arrays: a historical review of developments in mast cell research. Methods Mol Biol 315: 3-11.

13. Moon TC, St Laurent CD, Morris KE, et al. (2010): Advances in mast cell biology: new understanding of heterogeneity and function. Mucosal Immunol 3: 111-128.

14. Johansson A, Rudolfsson S, Hammarsten P, et al. (2010): Mast cells are novel independent prognostic markers in prostate cancer and represent a target for therapy. Am J Pathol 177: 1031-1041.

15. Knapczyk-Stwora K, Grzesiak M, Duda M, et al. (2013): Effect of flutamide on folliculogenesis in the fetal porcine ovary - regulation by Kit ligand/c-Kit and IGF1/IGF1R systems. Anim Reprod Sci 142: 160-167.

16. Copeland NG, Gilbert DJ, Cho BC, et al. (1990): Mastcell growth factor maps near the steel locus on mouse chromosome 10 and is deleted in a number of steel alleles. Cell 63: 175-183.

17. Figueira MI, Correia S, Vaz CV, et al. (2016): Estrogens down-regulate the stem cell factor (SCF)/c-KIT system in prostate cells: Evidence of antiproliferative and proapoptotic effects. Biochem Pharmacol 99: 73-87.

18. Riemann A, Schneider B, Gekle M, et al. (2011): Acidic Environment Leads to ROS-Induced MAPK Signaling in Cancer Cells. PLoS One 6: e22445.

19. Gupta S, Takebe N, Lorusso P, et al. (2010): Targeting the Hedgehog pathway in cancer. Ther Adv Med Oncol 2: 237250.

20. Chen CD, Sawyers CL (2002): NF-kappaB activates prostate-specific antigen expression and is upregulated in androgen-independent prostate cancer. Mol Cell Biol 22: 28622870.

21. Hsu A, Bray TM, Ho E, et al. (2010): Anti-inflammatory activity of soy and tea in prostate cancer prevention. Exp Biol Med 235: 659-667.

22. Mitselou A, Galani V, Skoufi U, et al. (2016): Syndecan-1, Epithelial-Mesenchymal Transition Markers (E-cadherin/ $\beta$-catenin) and Neoangiogenesis-related Proteins (PCAM-1 and Endoglin) in Colorectal Cancer. Anticancer Res 36: 22712280.

23. Xie F, Liu J, Li C, et al. (2016): Simvastatin blocks TGF- $\beta 1$ induced epithelial-mesenchymal transition in human prostate cancer cells. Oncol Lett 11: 3377-3383. 